\title{
Avaliação reológica de ligante modificado com Politereftalato de etileno (PET)
}

\author{
Rheological evaluation of binder modified \\ with Micronized Polyethylene Terephthalate (PET)
}

\begin{abstract}
José de Arimatéia Almeida e Silva ${ }^{1}$, John Kennedy Guedes Rodrigues ${ }^{2}$, Maria Wilma de Carvalho ${ }^{3}$, Lêda Christiane de Figueirêdo Lopes Lucena ${ }^{2}$, Erinaldo Hilário Cavalcante ${ }^{2}$
\end{abstract}

\footnotetext{
${ }^{1}$ Doutor, pesquisador. Laboratório de Engenharia de Pavimentos LEP/DEC/UFCG , Campina Grande, PB e-mail: arimateia.allmeida@gmail.com

${ }^{2}$ Professor de Engenharia Civil. Laboratório de Engenharia de Pavimentos LEP/DEC/UFCG. e-mail: profkennedy@ hotmail.com, ledach@uol.com.br, erinaldohc@gmail.com

${ }^{3}$ Professor de Engenharia Química. Universidade Federal de Campina Grande
}

\section{RESUMO}

Durante anos, o desempenho do ligante asfáltico utilizado puro foi considerado satisfatório. Entretanto, com o aumento do tráfego e das variações climáticas, tornou-se necessário o uso de agentes modificadores para melhorar as propriedades das misturas asfálticas. Dentre os modificadores mais utilizados na pavimentação, destaca-se o uso de polímeros, que se dividem em duas categorias: plastômeros e elastômeros. O modificador utilizado nesse trabalho foi o Politereftalato de Etileno (PET) que é um polímero de cadeia longa, pertencente à família genérica poliésteres, e são formados a partir dos intermediários, ácido tereftálico (TPA) e do etilenoglicol (EG). O PET utilizado foi o de formato micronizado, pós-consumo, na faixa entre 0,6 e 0,074 $\mathrm{mm}$. As caracterizações químicas e físicas do PET foram realizadas segundo a metodologia prevista na ASTM D1921-9601/2001. Os ensaios reológicos foram realizados com amostras puras do ligante e da mistura do ligante com PET, na proporção de $5 \%$ de PET em peso do ligante asfáltico 50/70. Analisou-se propriedades reológicas tais como o comportamento reológico dinâmico, a estabilidade de armazenamento de alta temperatura e propriedades de envelhecimento dos ligantes modificados. Demonstrou-se que o ligante modificado apresentou comportamento superior ao ligante convencional em todos os ensaios realizados.

Palavras-chave: reologia, resíduo, polímero, PET

\begin{abstract}
The performance of asphalt binder used neat was considered satisfactory until the end of 20 century. However, the increase of traffic and weather changes became necessary the use of additives to improve the properties of asphalt mixtures. Polyethylene terephthalate (PET) post-consumer micronized can be added in the traditional modified asphalt binders. With regarding to PET chemical, it is a long chain polymer, belonging to the generic family polyesters, and are formed from the intermediates, terephthalic acid (TPA) and ethylene glycol (EG). PET is then ground to a uniform particle size ranging from 0,6 to $0,074 \mathrm{~mm}$. The chemical and physical characterization of the waste were performed according to ASTM D1921-9601 / 2001 standards. The rheological tests were performed with pure samples of the binder and a mixture of the binder + PET. The content of PET was $5 \%$ by weight of the asphalt binder 50/70. Physical properties, such as dynamic rheological behavior, high temperature storage stability and aging properties of the modified asphalt were investigated. It was demonstrated that the modified binders outperformed the conventional binders at all the test conditions.
\end{abstract}

Keywords: rheology, residue, polymer

\section{INTRODUÇÃO}


A destilação do Petróleo gera como subproduto o ligante asfáltico, material amplamente utilizado em obras de pavimentação em todo o mundo, por apresentar propriedades de adesividade e aglutinação dos agregados [1]. Durante muitos anos, o desempenho do ligante asfáltico utilizado puro foi considerado satisfatório. Entretanto, com o aumento do tráfego e das variações climáticas, tornou-se necessário o uso de agentes modificadores para melhorar as propriedades reológicas de um ligante, e, consequentemente, o desempenho das misturas asfálticas.

Os modificadores são incorporados ao ligante asfáltico para melhorar a resistência a fadiga e a deformação permanente, diminuir a susceptibilidade térmica e aumentar a resistência ao trincamento em baixas temperaturas [2-3]. Estes modificadores atuam nas propriedades físicas e reológicas dos ligantes asfálticos. Entretanto, esta interação é complexa, pois varia de um comportamento viscoso para viscoelástico em função da taxa de carregamento e temperatura.

Dentre os modificadores mais utilizados na pavimentação, destaca-se o uso de polímeros, que se dividem em duas categorias: plastômeros e elastômeros. Os plastômeros mais comuns são: polietileno (PE) [4-5], polipropileno (PP) [6], acetato de vinila (EVA) [7], etileno-butil acrilato (EBA) [8] e polímeros elastoméricos (e.g. copolímero de estireno e butadieno) (SBS) [9], estireno-isopreno-estireno (SIS) [10] e estireno-etilenobutileno-estireno (SEBS) [11].

Os polímeros são frequentemente utilizados para modificar os ligantes asfálticos para melhorar propriedades reológicas como: estabilidade no armazenamento, rigidez à flexão, flexibilidade a baixas temperaturas e aumento da resistência à fissuração em baixas temperaturas [12-14].

O politereftalato de etileno (PET) é um polímero de cadeia longa, pertencente à família genérica poliésteres, e são formados a partir dos intermediários, ácido tereftálico (TPA) e do etilenoglicol (EG), que são ambos derivados de matérias-primas de petróleo. Em sua forma mais pura, é um material vítreo, amorfo, e que sob a influência da modificação direta como aditivos, desenvolvem cristalinidade. $\mathrm{O}$ alto preço de polímeros in natura e a mão de obra barata se constituem em aspectos potencializadores da reciclagem de resíduos de plásticos.

Entretanto, esse plastômero é de difícil reutilização ou até mesmo reciclagem. A sua reutilização na mesma cadeia produtiva é inviável, visto que os recipientes tipo PET são mais propensos a absorver contaminantes que podem ser liberados ou contaminar os alimentos quando são encapsulados. As impurezas contidas no PET micronizado, pós consumo, promovem a cristalização do polímero durante o arrefecimento, aumentando a rigidez do produto [15].

Outro tópico importante que contribui para melhorar as propriedades do PET e os seus efeitos no asfalto é o ajuste da sua estrutura molecular. Em relação ao comportamento do PET associado às misturas asfálticas, em moldes transparentes e amorfos, quando fundido e arrefecido rapidamente, o PET mantém o estado alongado. Em seguida, a sua microestrutura é enriquecida, com sua cadeia polimérica restante intacta. Uma vez definida essa fase de estado enrijecida, o material é extremamente resistente e confere propriedades melhoradas aos asfaltos [16].

Quando aquecido a uma temperatura de $72{ }^{\circ} \mathrm{C}$, sua forma é lentamente cristalizada, e o material começa a tornar-se opaco, mais rígido e menos flexível. Essa fase seguinte é conhecida como o PET cristalino. Ao adquirir essa forma, o material se torna capaz de resistir a temperaturas mais elevadas, e pode ser adicionado ao ligante asfáltico, promovendo maiores ganhos de resistência a deformações permanentes.

Os ensaios convencionalmente utilizados no estudo dos ligantes asfálticos possuem algumas limitações, como o uso de uma única temperatura de ensaio e a baixa aplicabilidade dos resultados. Portanto, as especificações do Superior Performing Asphalt Pavements (SUPERPAVE) determinam a realização de ensaios reológicos para determinar os parâmetros $\mathrm{G}^{*} / \sin \delta$ e compliâncias não-recuperáveis Jnr obtidos por meio do ensaio de fluência e recuperação sob tensão múltipla (MSCR) [17].

Dessa forma, a caracterização do PET e os ensaios reológicos são ferramentas importantes para determinar a compatibilidade entre os materiais, e, consequentemente, a viabilidade do uso do ligante modificado, sendo este o objeto de estudo ensejado neste trabalho. 


\section{MATERIAL E MÉTODOS}

\subsection{Material}

O ligante asfáltico utilizado na pesquisa foi do tipo 50/70, com propriedades de acordo com o regulamentado pela Agência Nacional de Petróleo (ANP), a qual define os parâmetros de aceitação e classificação. As especificações deste ligante encontram-se na Tabela 1.

O polímero adicionado ao ligante asfáltico foi do tipo micronizado pós-consumo, ou seja, um resíduo sólido, classificado como um plastômero, denominado de PET. O produto foi adquirido na indústria "De PET Reciclagem", localizada no município de Campina Grande, Estado da Paraíba.

As propriedades do PET micronizado dependem da sua natureza química. O tamanho das partículas de PET micronizado utilizado como agregado para a preparação de misturas asfálticas situa-se na faixa entre 0,6 e 0,074 mm. Desse total, a fração passante na peneira de $0,074 \mathrm{~mm}$ foi igual a 4,06\%.

A produção do PET micronizado ocorreu a partir de um procedimento físico, em que navalhas são utilizadas em um equipamento com a finalidade de triturar as garrafas PET em pequenas partículas, cujo processo recebe a denominação de micronização.

Tabela 1: Propriedades físicas do ligante asfáltico utilizado na pesquisa

\begin{tabular}{ccc}
\hline DESCRIÇÃO & RESULTADO & NORMA \\
\hline Penetração 0,1 mm $\left(100 \mathrm{~g}, 5 \mathrm{~s}\right.$ a $\left.25^{\circ} \mathrm{C}\right)$ & 52,9 & NBR 6576 \\
Ponto de Fulgor $\left({ }^{\circ} \mathrm{C}\right)$ & 320,0 & NBR 5765 \\
Densidade $\left(\mathrm{g} / \mathrm{cm}^{3}\right)$ & 1,02 & NBR 6568 \\
Ponto de Amolecimento $\left({ }^{\circ} \mathrm{C}\right)$ & 39,6 & NBR 6560 \\
Viscosidade Saybolt Furol $(\mathrm{s})$ & $310\left(\right.$ à $\left.135^{\circ} \mathrm{C}\right)$ & \\
& $377,5\left(\right.$ à $\left.135^{\circ} \mathrm{C}\right)$ & \\
Viscosidade Brookfield $(\mathrm{cP})$ & $187,0\left(\right.$ à $\left.150^{\circ} \mathrm{C}\right)$ & \\
\end{tabular}

\subsection{Métodos}

\subsubsection{Caracterização química e física do PET}

As caracterizações química e física do PET foram realizadas segundo critérios preconizados por normas, a partir da metodologia prevista na ASTM D1921-9601/2001.

Os ensaios para obtenção das curvas de difração de Raios X (DRX) foram realizados num Difratômetro, marca Siemens, modelo D - 5000, na faixa de $2 \theta=10-75^{\circ}$, com um passo de $0,02^{\circ}$ e tempo de passo de $1,0 \mathrm{~s}$, utilizando a radiação $\mathrm{K} \alpha$ do cobre como fonte de radiação monocromática, incidência normal, à temperatura ambiente. A cristalinidade foi obtida utilizando o software Pmgr da Shimadzu cristalinity, no qual é utilizado o Coeficiente de Correção de Lorentz.

As curvas de Termogravimetria (TG) e Análise Térmica Diferencial (ATD) foram obtidas em uma termo balança, marca Shimadzu, modelo DTG-60H - Simultaneous ATD-TG Apparatus, em atmosfera de nitrogênio, com cadinho de alumina, fluxo de $50 \mathrm{~mL} \cdot \mathrm{min}-1$, razão de aquecimento de $100{ }^{\circ} \mathrm{C}$.min-1, numa faixa de temperatura ambiente que pode variar até $900^{\circ} \mathrm{C}$. A massa utilizada foi em torno de 4,0 $\pm 0,5$ gramas.

As curvas DSC foram obtidas em um equipamento TA INSTRUMENTS, modelo DSC 2920 Modulated DSC, com o objetivo de se medir as transições entálpicas dos complexos, em atmosfera de nitrogênio com cadinho de alumina, fluxo de $50 \mathrm{~mL} \cdot \mathrm{min}^{-1}$ e razão de aquecimento de $100{ }^{\circ} \mathrm{C} \cdot \mathrm{min}^{-1}$, numa faixa de temperatura que varia da ambiente até $7000^{\circ} \mathrm{C}$. A massa utilizada foi em torno de $4.0 \pm 0.5$ gramas.

\subsubsection{Ensaios reológicos das amostras do ligante}

Os ensaios reológicos foram realizados com amostras puras do ligante e da mistura do ligante com PET, na proporção de 5\% de PET em peso do ligante asfáltico 50/70, cujos resultados referentes à caracterização físi- 
ca e ao envelhecimento apresentaram melhores resultados quando comparados aos do ligante puro, conforme apresentado por Silva et. al. [18].

O processo empregado na adição do modificador PET ao ligante asfáltico foi combinado a partir de técnicas de mistura com rotações de $2000 \mathrm{rpm}$, sob temperatura de $165^{\circ} \mathrm{C}$, com um tempo de mistura de 2 horas, em um misturador de asfalto Modelo 722D. As amostras do ligante puro foram denominadas CAP 50/70 e as modificadas com PET receberam a denominação de 5\% PET nas análises dos resultados.

O comportamento viscoelástico do ligante asfáltico foi avaliado por meio da aplicação de tensão de cisalhamento oscilatória, com variação de frequência (10-2 a 102) ou temperatura (46, 52, 58, 64, 70, 76, 82 e $88^{\circ} \mathrm{C}$ ). A partir disso, determinou-se o Módulo Complexo G*, Módulo Elástico G', Módulo Viscoso G”, o ângulo de fase " $\delta$ " e a viscosidade aparente. Os ensaios no Reômetro de Cisalhamento Dinâmico, modelo DHR-1, foram realizados de acordo com a norma da ASTMD7175/2008.

Realizou-se o ensaio de Fluência e Recuperação sob Tensão Múltipla (MSCR - Multiple Stress Creep and Recovery), que resultou do aperfeiçoamento do ensaio de Fluência Repetida e Recuperação (RCRT Repeated Creep and Recovery), desenvolvido pela Administração Rodoviária Federal dos Estados Unidos (FHWA - Federal Highway Administration). Esse ensaio teve como objetivo avaliar o percentual de recuperação, a compliância não-recuperável e a dependência dos ligantes, especialmente os modificados, quanto ao nível de tensão, seguindo-se a especificações da norma ASTM D7405/2010.

\section{RESULTADOS E DISCUSSÕES}

\subsection{Caracterização química e física do PET}

A Figura 1 apresenta os resultados do ensaio de Difratograma de Raios X (DRX) do PET micronizado pós consumo. O PET micronizado é caracterizado pela opacidade, propriedade ótica típica de materiais cristalinos. Portanto, embora o PET seja um material polimérico, o gráfico obtido do DRX revela ordenação cristalina do material, similar ao encontrado por Vanini[19] que também estudou esse material. Os picos cristalográficos do DRX se devem à presença de traços de impurezas presentes no produto, provavelmente provenientes do uso anterior do polímero.

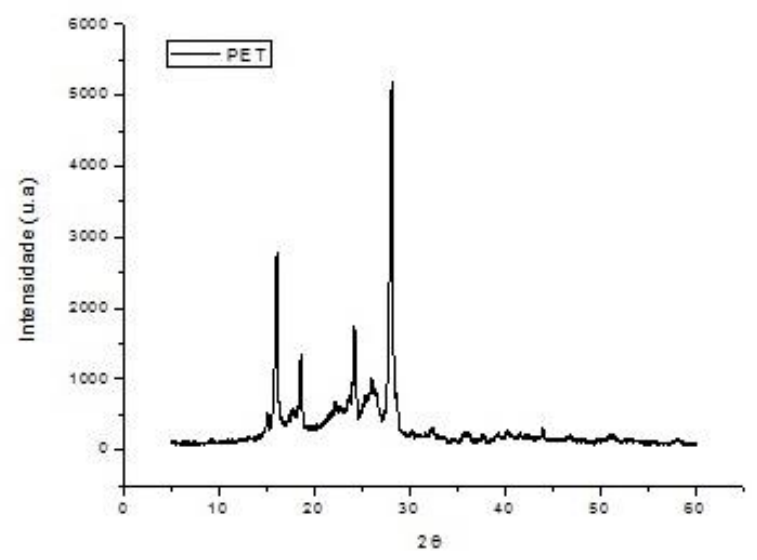

Figura 1: DRX para o PET micronizado pós consumo

O gráfico obtido do ensaio de Calorimetria Exploratória Diferencial (DSC) realizado com o PET micronizado pós consumo está mostrado na Figura 2. De acordo com a curva obtida, pode-se observar que as mudanças químicas na cadeia polimérica do PET ocorrem para temperaturas acima de $200^{\circ} \mathrm{C}$, ou seja, acima dos valores usados na usinagem e aplicação dos ligantes asfálticos, que no máximo, atinge os $165^{\circ} \mathrm{C}$. Tais condições garantem que durante o processo de mistura o PET mantém suas propriedades originais, conforme observado por Rabello[20]. Para o presente caso, as alterações químicas no fluxo de calor do PET ocorreriam a partir da temperatura de $250{ }^{\circ} \mathrm{C}$, aproximadamente. 


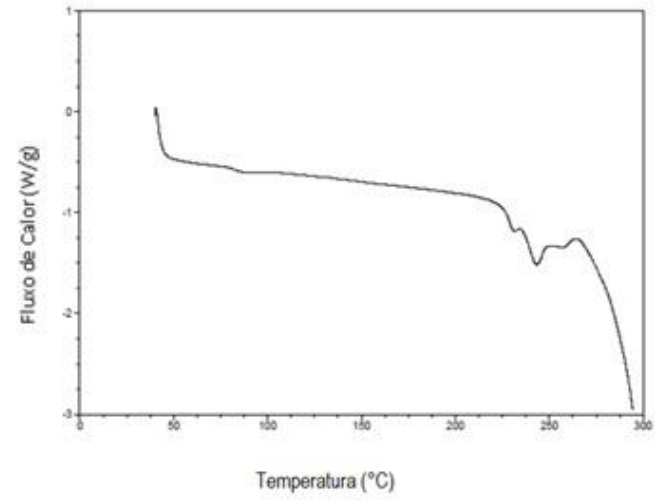

Figura 2: DSC para o PET micronizado pós consumo

Os resultados das análises termogravimétricas, utilizadas para medir a variação da perda de massa durante o aquecimento da amostra de PET micronizado pós consumo estão apresentados na Figura 3. Analisando-se os resultados, observa-se que a massa do PET diminuiu com o aumento da temperatura, e que essa tendência se iniciou sob $32^{\circ} \mathrm{C}$, aproximadamente. Verifica-se também que até aproximadamente $83{ }^{\circ} \mathrm{C} \mathrm{o}$ material apresenta mudança do estado sólido para o estado líquido, havendo uma perda da massa do PET. Tais condições corroboram para uma melhor homogeneização do processo de mistura entre o ligante asfáltico e o PET. Estes resultados são similares aos obtidos por Souza [21].

Verifica-se, na Figura 3, uma perda de massa expressiva até a temperatura de $83{ }^{\circ} \mathrm{C}$, após esta observa-se um discreto aumento na massa do PET, indicando que uma nova mudança de estado físico ocorreu (líquido para vapor). Ao final do ensaio verificou-se uma perda total de massa de $0,24 \%$.

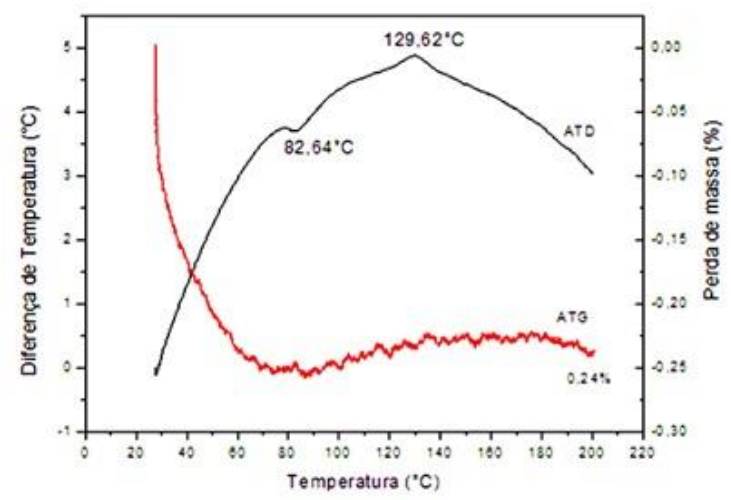

Figura 3: Análises de Termogravimetria (TG) / Análise Térmica Diferencial (ATD)

\subsection{Ensaios reológicos das amostras do ligante}

A adição de polímeros a ligantes asfálticos promove variações significativas na viscoelasticidade destes. De acordo com Xue et al. [22] esse fato merece uma atenção especial pois existe uma forte correlação entre a resistência à deformação e o módulo de elasticidade sob altas temperaturas. Portanto, o estudo reológico dos ligantes modificados é imprescindível para se verificar a resposta do ligante a essa adição. 
Os resultados lançados em gráficos contidos na Figura 4 indicam a variação do parâmetro G*.sen $\delta$ em função da temperatura, antes do envelhecimento simulado Rolling Thin-Film Oven (RTFO), para as amostras estudadas: ligante asfáltico puro (CAP 50/70) e ligante asfáltico com adição de 5\% de PET (5\% PET). .

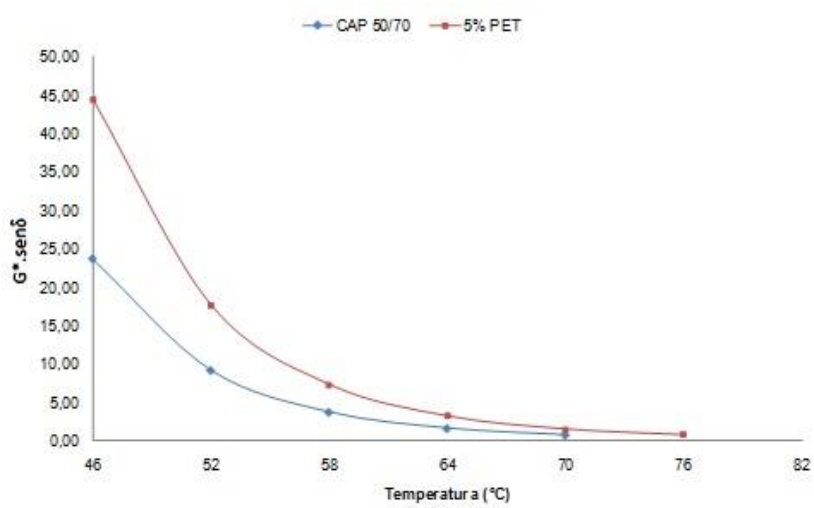

Figura 4: Relação do parâmetro $\mathrm{G}^{*}$. sen $\delta$ em função da temperatura.

A associação do Módulo Complexo com o ângulo de fase ( $\mathrm{G}^{*}$. sen $\left.\delta\right)$ é um critério de avaliação da resistência do ligante à fadiga (conforme adotado pelo Strategic Highway Research Program- SHRP). De acordo com o gráfico mostrado na Figura 4, o ligante asfáltico puro sofreu uma perda na resistência à fadiga maior do que o ligante asfáltico modificado com 5\% de PET. Entretanto destaca-se que essa analogia entre o ângulo de fase e a resistência a fadiga não tem-se mostrado representativa, sendo substituída pelo ensaio de LAS.

A Figura 5 apresenta os resultados da variação do parâmetro $\mathrm{G}^{*} / \mathrm{sen} \delta$ em função da temperatura do ligante para as amostras estudadas após o RTFO. A relação do Módulo Complexo com o ângulo de fase $\left(\mathrm{G}^{*} / \mathrm{sen} \delta\right)$ é um critério de avaliação da resistência do ligante à deformação permanente, conforme adotado pelo SHRP. O ligante asfáltico puro apresentou menor resistência à deformação permanente do que o ligante asfáltico modificado com 5\% de PET. Pode-se inferir com isso que o desempenho do ligante asfáltico modificado foi superior ao ligante asfáltico puro em termos reológicos, tomando-se como parâmetros os ensaios supracitados.

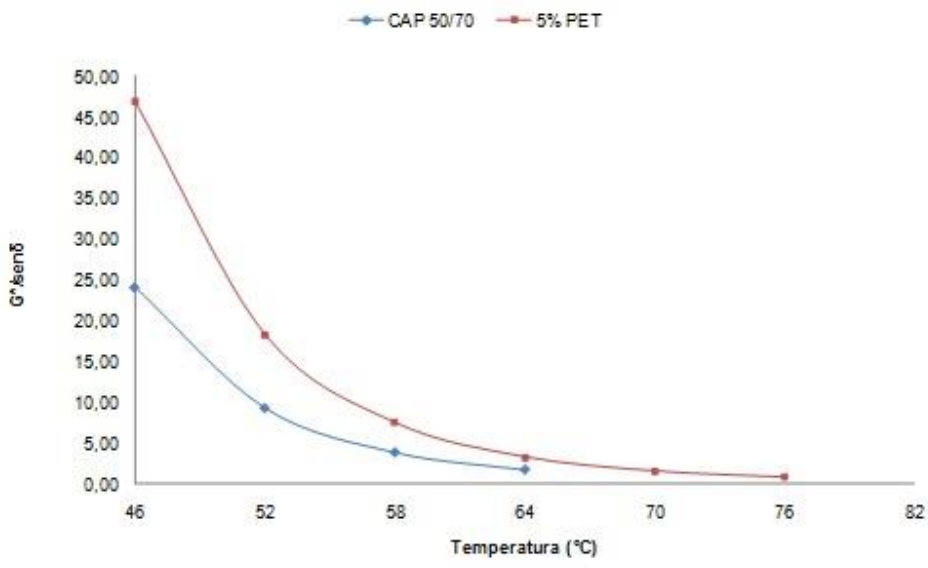

Figura 5: Parâmetro G*/ sen $\delta$ em função da temperatura após o RTFO

A Figura 6 apresenta os Graus de Desempenho (PG) obtidos com os ligantes asfálticos puro e modificado antes e após o RTFO. Vale mencionar que o Grau de Desempenho (PG) de um ligante asfáltico é definido por duas temperaturas que delimitam a faixa de utilização do mesmo: i) uma indicando a temperatura máxima para uso, de forma a manter um desempenho satisfatório (baixa deformação permanente); e ii) outra indicando a temperatura mínima, de forma a evitar o trincamento por baixa temperatura. Entretanto, para este 
estudo em questão só foi verificada a temperatura máxima de uso do ligante asfáltico, uma vez que o país apresenta clima tropical e, portanto, não irá atingir temperaturas negativas.

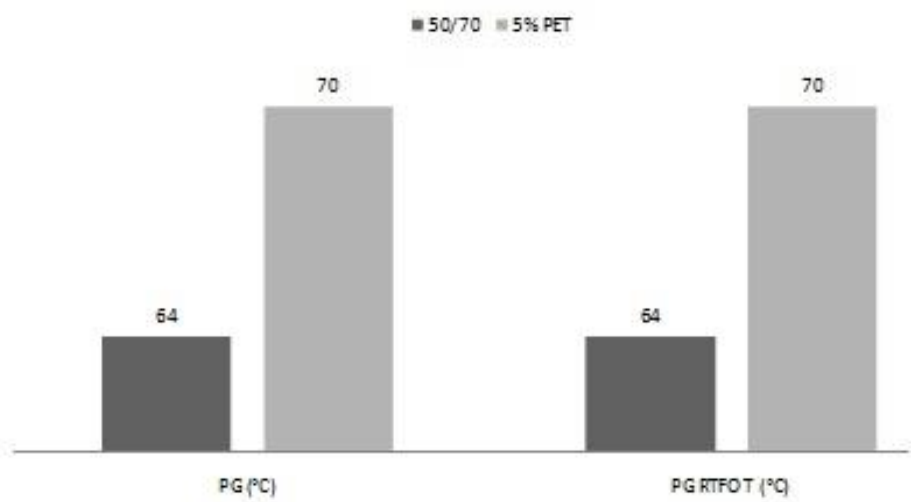

Figura 6: Graus de Desempenho (PG) dos ligantes asfálticos puro e modificado

De acordo com a especificação SUPERPAVE, os resultados de PG determinam, dentro de critérios pré-determinados, a faixa de temperatura de aplicação de um determinado ligante. Essa especificação sugere que a temperatura máxima recomendada para uso de um ligante asfáltico seja aquela na qual o valor da relação $\mathrm{G}^{*} / \mathrm{sen} \delta$ mostre-se superior a 1,0 kPa, antes do seu envelhecimento no RTFO, e superior a 2,2 kPa, após este ensaio.

De acordo com resultados apresentados na Figura 6, o ligante asfáltico puro utilizado nesta pesquisa apresentou propriedades reológicas adequadas até à temperatura de $64{ }^{\circ} \mathrm{C}$ e $70{ }^{\circ} \mathrm{C}$ quando se usou o ligante asfáltico modificado. Esse resultado é análogo ao observado por Butalovic and Marcovic [8] quando adicionaram polímeros a ligantes asfálticos. Vale mencionar que a literatura tem registrado que o ligante asfáltico modificado apresenta, em geral, PG superior ao ligante puro, o que resulta em melhor desempenho diante de condições climáticas "severas" e condições de tráfego pesado (volume e tempo de aplicação de carga) na região onde será aplicado.

A Figura 7 apresenta a variação do parâmetro $\mathrm{G}^{*} / \operatorname{sen} \delta$ em função da temperatura, de onde se pode observar o comportamento dos ligantes asfálticos puro e modificado, após o envelhecimento simulado (RTFO). De forma análoga aos resultados anteriores, os gráficos da Figura 7 comprovam que a vida útil do revestimento asfáltico modificado é superior ao do puro, visto que os valores do parâmetro $\mathrm{G}^{*} /$ sen $\delta$ do ligante asfáltico modificado com 5\% de PET são superiores aos do ligante asfáltico puro.

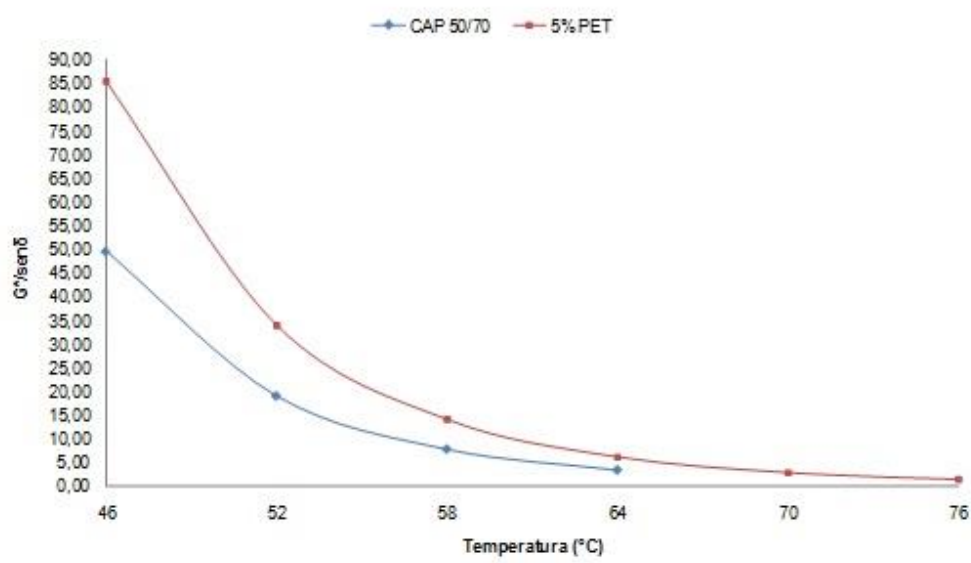

Figura 7: Parâmetro $G^{*} / \operatorname{sen} \delta$ em função da temperatura 
A Figura 8 apresenta a variação do parâmetro tangente $\delta$ em função da temperatura, enquanto que a Figura 9 mostra os valores do Módulo Complexo $\left(\mathrm{G}^{*}\right)$ versus a temperatura, para os ligantes asfálticos puro (CAP 50/70) e modificado (5\% PET).

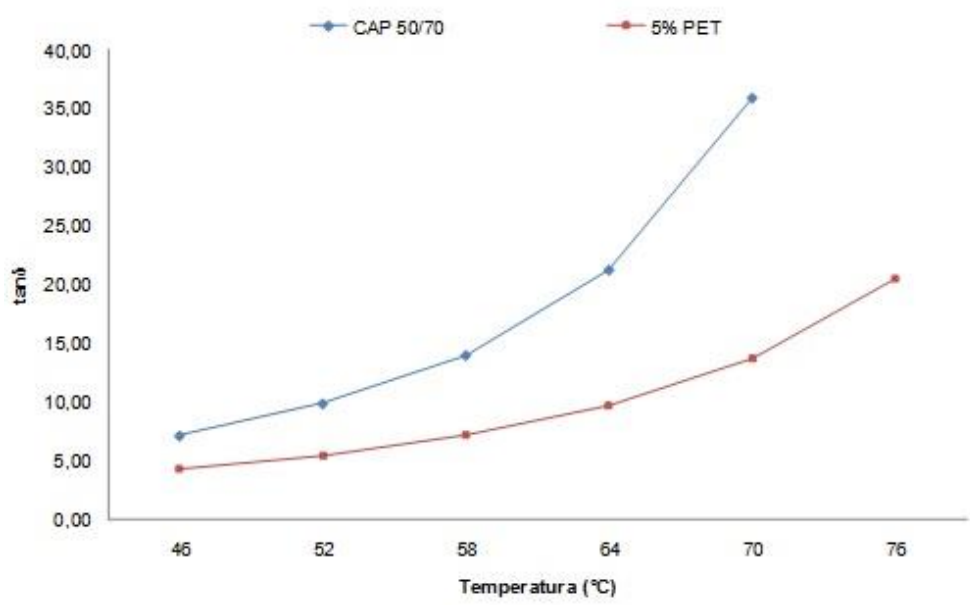

Figura 8: Parâmetro tan $\delta$ em função da temperatura

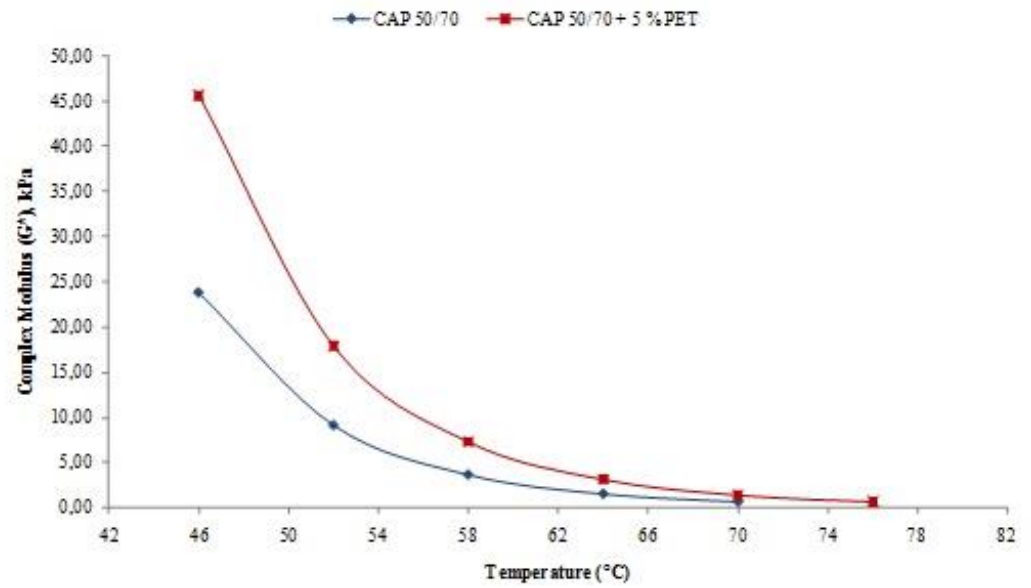

Figura 9: Parâmetro Módulo Complexo G* em função da temperatura

Em comparação ao ligante asfáltico puro, observa-se que o asfalto modificado apresentou módulo complexo maior e ângulo de fase menor com o aumento da temperatura. Estes resultados indicam uma maior rigidez do ligante com adição de 5\% de PET, ou seja, uma maior resistência à deformação plástica (Figura 8). Por outro lado, verifica-se que o módulo complexo diminuiu com o aumento de temperatura, ressaltando-se que a redução nos valores de $G^{*}$ foi mais acentuada para o ligante puro, enquanto o modificado suportou temperaturas próximas de até $10 \%$ maiores. A redução do ângulo de fase com a adição do PET indica uma mudança de comportamento viscoso para elástico do ligante asfáltico, uma vez que quanto menor o ângulo de fase maior o comportamento elástico do material. Estes resultados são similares ao encontrados por outros autores que também adicionaram polímeros a ligantes asfálticos[10, 22-23], nos quais eles verificaram aumento do módulo complexo e diminuição do ângulo de fase com a adição do polímero.

A Figura 10 apresenta as curvas de módulo complexo em função da frequência de cisalhamento para as amostras estudadas sob diferentes temperaturas e frequências. De acordo com as curvas da Figura 10, os 
resultados para ambas as amostras apresentam comportamentos similares. Entretanto a medida que se diminui a frequência desse intervalo, observa-se discreta diminuição da região de viscoelasticidade linear para o ligante asfáltico puro, enquanto que para valores de frequência acima de $10^{1} \mathrm{~Hz}$, observa-se a diminuição na viscoelasticidade linear do ligante asfáltico modificado.

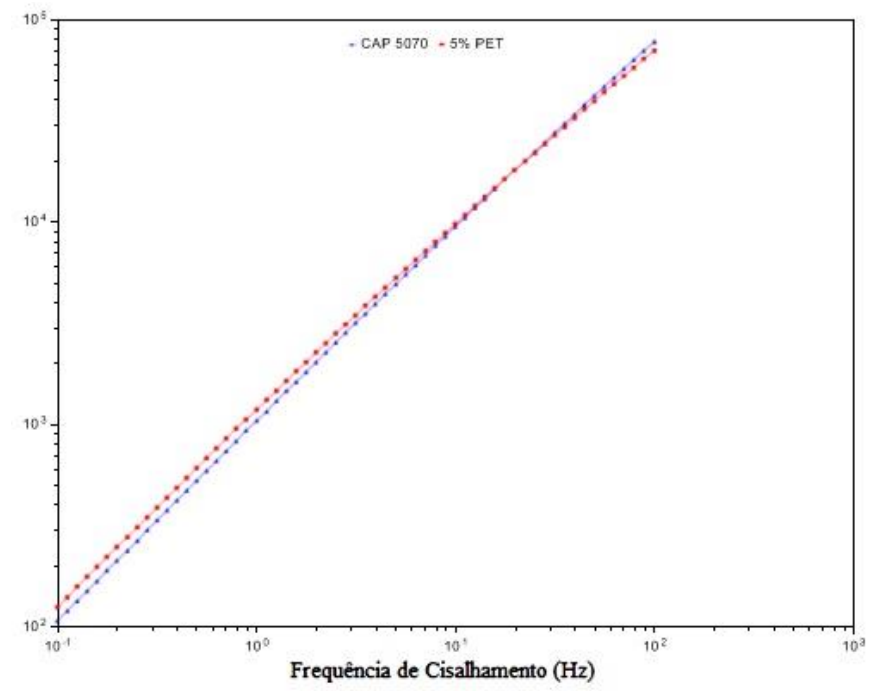

Figura 10: Módulo complexo em função da frequência de cisalhamento.

O MSCR foi utilizado neste estudo para caracterizar o comportamento fluência-recuperação dos ligantes asfálticos puro e modificado envelhecidos a curto prazo. Os resultados obtidos dos ensaios de MSCR realizados comas amostras indicam que estes ligantes possuem desempenhos satisfatórios quando submetidos a elevadas temperaturas.

A Figura 11 apresenta as relações entre os percentuais de recuperação para o ligante asfáltico puro e o ligante asfáltico modificado, considerando a condição envelhecida desses materiais e os níveis de tensões entre $100 \mathrm{~Pa}$ a $3.200 \mathrm{~Pa}$.

De acordo com os resultados obtidos, mostrados na Figura 11 é possível observar que os ligantes asfálticos puro e modificado mantém constante a deformação não recuperável após o aumento dos tempos de fluência e recuperação de 1 e $9 \mathrm{~s}$. Vale ressaltar que esse ensaio é utilizado para ligantes asfálticos modificados com elastômeros. No caso do PET, que se encontra na zona de rigidez, os resultados de MSCR podem ser utilizados como confirmação que o material se trata de um plastômero.

Os valores mínimos de percentual de recuperação podem ainda ser apresentados de forma gráfica, onde os pares ordenados acima da curva são considerados de alta elasticidade, enquanto que aqueles abaixo da curva são os de baixa elasticidade.

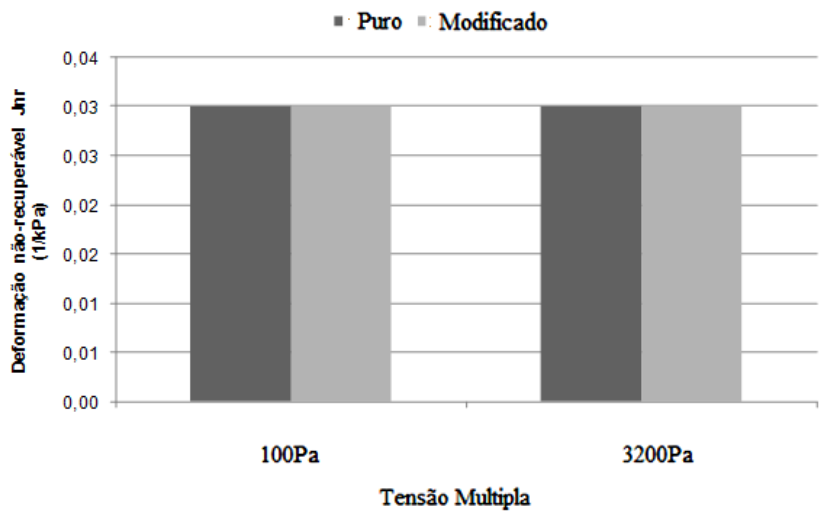

Figura 11: Gráficos de Fluência e Recuperação sobre Tensão Múltipla 
Na Figura 12 é apresentado o gráfico que relaciona o percentual de recuperação (\%) à compliância. Os resultados mostrados no gráfico revelam que tanto o ligante asfáltico puro quanto o modificado mantém as suas propriedades na zona de baixa elasticidade. Este fato era esperado, pois Silva et al. (2015), ao analisarem as propriedades físicas de ligantes modificados com PET, verificaram que a adição deste resíduo promove diminuição na recuperação elástica do material.

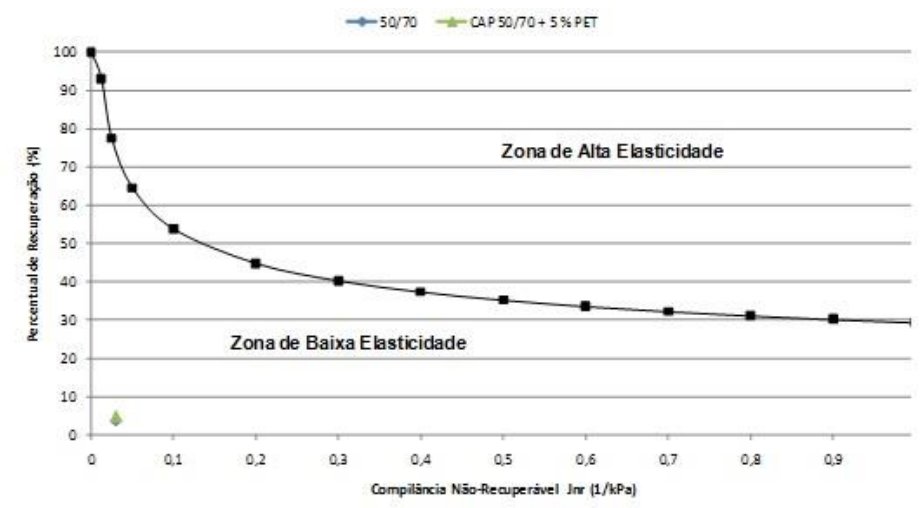

Figura 12: Percentual de recuperação (\%) em função da compliância

\section{CONCLUSÕES}

O estudo da adição de PET ao ligante asfáltico resultou no desenvolvimento de uma técnica para melhorar o desempenho dos pavimentos asfálticos. A adição do PET ao ligante compatibilizou uma fase de mistura heterogênea, apresentando um incremento nas propriedades reológicas do ligante.

Em termos de propriedades microestruturais, o PET micronizado pós consumo apresentou comportamento cristalino e mudanças de fase acima das temperaturas de usinagem dos ligantes. Este é um importante fator para garantir que a adição do resíduo não compromete a utilização do ligante em misturas asfálticas.

Em comparação ao ligante asfáltico puro, observa-se que o asfalto modificado apresentou módulo complexo maior e ângulo de fase menor com o aumento da temperatura. Estes resultados indicam uma maior rigidez do ligante com adição de 5\% de PET. A adição do resíduo promoveu o aumento mais expressivo do módulo elástico G' do que do componente viscoso G”, para o módulo complexo G*, ao passo que houve uma redução no envelhecimento do ligante.

Comparando-se os Graus de Desempenho (PG) obtidos, observou-se uma maior tolerância do ligante modificado à variação de temperatura do que o ligante asfáltico puro. De acordo com as propriedades reológicas, houve um incremento nos ligantes modificados de resistência a Fadiga $\left(\mathrm{G}^{*}\right.$. sen $\delta$ ) e deformação permanente $\left(\mathrm{G}^{*} /\right.$ sen $\left.\delta\right)$. Portanto, analisando o desempenho reológico de ligantes modificados com PET micronizado, verifica-se que esta é uma técnica promissora, entretanto necessita de ensaios complementares, em laboratório e in situ, para validação do uso desta.

\section{AGRADECIMENTOS}

Ao Laboratório de Engenharia de Pavimentos (LEP) do Departamento de Engenharia Civil da Universidade Federal de Campina Grande;

A Associação Técnico Científica Ernesto Luiz de Oliveira Junior (ATECEL) pela estrutura e equipamentos disponibilizados para a realização deste trabalho.

\section{BIBLIOGRAFIA}

[1] SULTANA, S., BHASIN, A. "Effect of chemical composition on rheology and mechanical properties of asphalt binder", Construction and Building Materials, v 72, pp. 293-300, 2014 
[2] PAMPlONA, T.F., AMONI, B.C., ALENCAR, A.E.V., et al., "Asphalt Binders Modified by SBS and SBS/Nanoclays: Effect on Rheological Properties”, Journal Brazilian Chemical Society, v. 23, n. 4, pp. 639647, 2012.

[3] SABOO, N., KUMAR, P. "A study on creep and recovery behavior of asphalt binders", Construction and Building Materials, v 96, pp. 632-640, 2015.

[4] ZHU, J., BIRGISSON, B., KRINGOS, N. "Polymer modification of bitumen: Advances and challenges", European Polymer Journal, v 54, pp.18-38, 2014.

[5] VARGAS, MA, VARGAS, MA, SANCHEZ-SOLIS, A., et al., "Asphalt/polyethylene blends: Rheological properties, microstructure and viscosity modeling", Construction and Building Materials, v 45. pp 24350,2013

[6] YUAN, CH, WANG, SF, ZHU, YQ, et al., "Properties of the asphalts modified by typical recycled polyolefin”, Polymer Mater Science Engineering, v 12. pp. 81-89, 2012

[7] GAMA, D. A., LUCENA, A.E.F.L., MONTEIRO, V. E. D., et al., "Verification of the effect of EVA s residues addition and the aging in mechanical properties of asphalt mixtures", Petroleum Science and Technology. v. 33, pp. 936-942, 2015.

[8] BULATOVIC', V.O., MARKOVIC, V.R. "Rheological Properties of Bitumen Modified With Ethylene Butylacrylate Glycidylmethacrylate", Polymer Engineering and Science, v 54. n 5, pp. 1056-1065, 2014

[9] KANG, Y., SONG M., PU, L., et al., "Rheological behaviors of epoxy asphalt binder in comparison of base asphalt binder and SBS modified asphalt binder", Construction and Building Materials, v 76, pp.343$350,2015$.

[10] CHEN, J.S., LIAO, M.C., SHIAH, M.S. “Asphalt Modified by Styrene-Butadiene-Styrene Triblock Copolymer: Morphology and Model”, Journal of Materials in Civil Engineering, v. 14, n. 3, pp.224-229, June 2002.

[11] RAHI, M., FINI, H., HAJIKARIMI, P., et al., "Rutting Characteristics of Styrene-Ethylene/ PropyleneStyrene Polymer Modified Asphalt”, Journal of Materials in Civil Engineering, v. 27, n.4, 2015.

[12] YILDIRIM, Y. "Polymer modified asphalt binders", Construction and Building Materials, v 21, n.1, pp. 66-72, 2007

[13] TAREFDER, R.A., YOUSEFI, S.S. "Rheological Examination of Aging in Polymer-Modified Asphalt". Journal of Materials in Civil Engineering, v. 28, n.2, 2015

[14] YAN, K., XU, H., YOU, L. "Rheological properties of asphalts modified by waste tire rubber and reclaimed low density polyethylene", Construction and Building Materials, v.83, pp. 143-149. 2015

[15] TAREFDER Rafiqul A., ZAMAN Arif M. "Nanoscale Evaluation of Moisture Damage in Polymer Modified Asphalts", Journal of Materials in Civil Engineering. v. 22, n.2, pp. 714-725, 2010.

[16] CARDOSO, Y. T. "Desenvolvimento de compósitos de poli (tereftalato de etileno) reciclado com fibras naturais", In: XXXIV Jornada Giulio Massarani de Iniciação Científica, Tecnológica, Artística e Cultural. Universidade Federal do Rio de Janeiro, 2012.

[17] DOMINGOS, M. D. I., FAXINA, A. L. "Susceptibility of Asphalt Binders to Rutting: Literature Review”, Journal of Materials in Civil Engineering, v.28, n.2, pp.1-18, 2015.

[18] SILVA, J.A.A., LUCENA, L.C.F.L., RODRIGUES, J.K.G., et al., "Use of Micronized Polyethylene. Terephthalate (Pet) Waste in Asphalt Binder", Petroleum Science and Technology, v 33, pp.15-16, pp.1508$1515,2015$.

[19] VANINI, G., SILVA FILHO, E. A., "Reciclagem do PET por despolimerização em meio alcalino na presença do tensoativo CTAB e comparação com o Método Petretec", In: Iniciação Científica. Universidade Federal do Espírito Santos, 2010.

[20] RABELLO, M.S., WELLEN, R. M. R. "Estudo da cristalização a frio do poli (tereftalato de etileno) (PET) para produção de embalagens”, Revista Eletrônica de Materiais e Processos, v.3 n.2. pp. 1-9, 2008

[21] SOUZA, J. K.D. Síntese de Catalisadores Utilizando Garrafa Pet Para a Produção de Biodiesel. Dissertação de M.Sc., Universidade Federal da Paraíba. João Pessoa, PB, Brasil, 2012.

[22] XUE, Y., WU, S., ZHOU, M., et al.,"Effects of two biomass ashes on asphalt binder: Dynamic shear rheological characteristic analysis", Construction and Building Materials , v.56. pp 7-15, 2014

[23] LIANG, M., XIN, X., LUO, H., et al., "Investigation of the rheological properties and storage stability of CR/SBS modified asphalt", Construction and Building Materials, v. 74. pp 235-240, 2015. 